\title{
THE NATIONAL CATARACT SURGERY SURVEY: III. PROCESS FEATURES
}

\author{
PARUL DESAI \\ London
}

\begin{abstract}
SUMMARY
The process of how medical care is provided for cataract patients within the National Health Service is reported in this paper with particular emphasis on features relating to access to surgery and delivery of the surgical service. Access to the hospital eye service is considered in terms of lengths of waiting time and level of visual impairment at specific periods of patient care: first assessment in an ophthalmic out-patient clinic, at listing for surgery and for admission for surgery. Delivery of the surgical service is considered in terms of threshold of visual acuity at which surgery is considered necessary and some features of post-operative management: length of stay, duration of post-operative medication, number of post-operative outpatients visits and whether final refraction had been performed and spectacles dispensed by 3 months after surgery. Regional operation rates are presented as indicators of activity. These results describe the experience of a sample of all patients admitted for cataract surgery in 1990 and provide national figures for the process features considered in this report with respect to current surgical practice in the United Kingdom.
\end{abstract}

The National Cataract Surgery Survey was conducted in 1990 to obtain data on current surgical activity for agerelated cataract in the United Kingdom (UK). It has shown that microsurgical techniques for extracapsular cataract extraction with intraocular lens implantation are now the procedures of choice routinely offered to patients with age-related cataract ( $91 \%$ of cases), predominantly on an in-patient basis (92\% of cases). ${ }^{1}$ Process features of the surgical procedure itself (how surgical care is provided during the patient's admission episode) have been reported earlier. ${ }^{1}$ These surgical methods are associated with a best corrected post-operative visual acuity of $6 / 12$ or better at 3 months, in $80 \%$ of all patients having cataract surgery. Sight-threatening surgically related complications are rare events. ${ }^{2}$

This paper reports on the process of how medical care is

Correspondence to: Parul Desai, MSc, FRCS, FRCOphth, Royal College of Ophthalmologists, 17 Cornwall Terrace, Regent's Park, London NW1 4QW, UK. provided for this common intervention regarding access to surgery and delivery of the surgical service.

\section{METHOD}

The National Cataract Surgery Survey was a prospective cross-sectional survey of National Health Service (NHS) patients of 50 years of age and over who had surgery for age-related cataract in the UK during the survey period. All consultants who regularly performed surgery for agerelated cataract were eligible for participation in the survey and were invited to provide clinical data on all patients admitted under their care for cataract surgery during the survey period. All adult NHS patients admitted for surgery for age-related cataract were eligible for inclusion. Those patients undergoing combined procedures or surgery for other types of cataract were excluded. This provided a cohort of patients admitted for cataract surgery with information of their experience with the existing surgical service. Data collection and survey methods have been reported earlier. ${ }^{1}$ Pre- and post-operative clinical data were collected on standardised proforma and patients were followed up for 3 months after surgery for short-term clinical outcomes.

Access to the hospital eye service was considered in terms of waiting time and level of visual impairment at specific periods during patient care: on presentation at the first out-patient assessment, on listing for surgery and on admission for surgery.

Waiting times were calculated for each patient. Waiting time for the first out-patient assessment was taken as the interval between the date of referral to hospital and the date first seen in an ophthalmic out-patient clinic. Time waited for listing was taken as the time since first assessment in the out-patient clinic and the date surgery was offered (it was assumed that the patient accepted the offer of surgery on this date otherwise he or she would not have been placed on the list). The time waiting for surgery was taken as the time from date of listing to that of admission. All waiting times are reported in months.

All visual acuities are reported as the best corrected (with correction or pin-hole) Snellen acuity. 
Table I. Distribution of waiting times

\begin{tabular}{|c|c|c|c|c|c|c|}
\hline \multirow{2}{*}{$\begin{array}{l}\text { Time } \\
\text { (months) }\end{array}$} & \multicolumn{2}{|c|}{ First out-patient assessment } & \multicolumn{2}{|c|}{ Listing for surgery } & \multicolumn{2}{|c|}{ Admission for surgery } \\
\hline & $n$ & $\%$ & $n$ & $\%$ & $n$ & $\%$ \\
\hline$\leqslant 3$ & 543 & 56 & 549 & 56 & 309 & 32 \\
\hline $4-6$ & 261 & 27 & 48 & 5 & 261 & 27 \\
\hline $7-9$ & 93 & 9 & 41 & 4 & 127 & 13 \\
\hline $10-12$ & 30 & 3 & 35 & 4 & 110 & 11 \\
\hline$>12$ & 48 & 5 & 302 & 31 & 168 & 17 \\
\hline Total & 975 & 100 & 975 & 100 & 975 & 100 \\
\hline
\end{tabular}

Median wait for first out-patient assessment $=2.64$ months.

Median wait for listing for surgery $=0$ months.

Median wait for admission for surgery $=4.8$ months.

Delivery of the surgical service with respect to how care was provided was considered in terms of threshold (visual acuity) at which surgery was considered necessary, postoperative management and regional operation rates.

The features of post-operative care considered included length of stay in hospital, duration of post-operative medication, number of post-operative out-patient visits and whether a final refraction and spectacles had been dispensed by 3 months after surgery. Length of stay in hospital (number of days) is reported only for in-patients and was taken to be the time between the date of admission and the date of discharge from hospital after the operation. Duration of post-operative medication was calculated from the date of discharge after the operation to the date medication was discontinued.

The NHS is geographically divided into regions for administrative purposes. England constitutes fourteen regions and Wales one region; Scotland and Northern Ireland also constitute a single administrative region each, making a total of seventeen regions. In addition there are several special health authorities providing eye health care, but only one provided a regular surgical service for age-related cataract at the time of the survey; $90.3 \%$ of cataract operations performed by this special health authority included in the survey were for patients from the four Thames regions in England (North West Thames, North East Thames, South West Thames and South East Thames). ${ }^{3}$ The regional figures (rates and number of consultants regularly performing surgery for age-related cataract) presented reflect this distribution of cataract cases.

The survey data provided weekly regional operation rates which are presented per 100000 of the regional population of 50 years of age and over. These weekly rates were then used to estimate annual regional operation rates by taking 48 weeks as a working year. Age-standardised rates (weekly and annual) were determined for each region by direct standardisation using the UK population estimate of persons 50 years of age and over for 1990 as the standard. ${ }^{4}$

The population of 50 years of age and over was taken as it represented those who were most likely to require a cataract operation. Regional population estimates for this age group for 1990 were obtained from the Office of Population Censuses and Surveys (OPCS), the Scottish Home and Health Office and from the Department of Health and Social Services, Office of the Registrar General for Northern Ireland.

The $95 \%$ confidence intervals around proportions were calculated by the normal approximation to the binomial distribution for large proportions and by the exact method for smaller ones. ${ }^{5}$ Rate ratios were determined by Poisson regression analysis using the EGRET (Epidemiological Graphics, Estimation and Tabulation) software.

\section{RESULTS}

In total 975 records were suitable for the analysis required for this report and represented $82 \%(n=1182)$ of all paired patient records for pre- and post-operative data.

\section{Access to Surgery}

\section{Waiting Times}

The distribution of the waiting times experienced by the

Table II. Distribution of best visual acuity in eye having surgery

\begin{tabular}{|c|c|c|c|c|c|c|}
\hline \multirow[b]{2}{*}{ Visual acuity } & \multicolumn{2}{|c|}{ At first OPD assessment } & \multicolumn{2}{|c|}{ At listing for surgery } & \multicolumn{2}{|c|}{ On admission for surgery } \\
\hline & $n$ & $\%$ & $n$ & $\%$ & $n$ & $\%$ \\
\hline $6 / 6$ to $6 / 12$ & 251 & 30 & 91 & 11 & 59 & 7 \\
\hline $6 / 18$ to $6 / 24$ & 240 & 28 & 270 & 32 & 226 & 27 \\
\hline $6 / 36$ to $6 / 60$ & 162 & 19 & 214 & 25 & 200 & 24 \\
\hline $3 / 60$ to $\mathrm{HM}$ & 190 & 23 & 268 & 32 & 358 & 42 \\
\hline Total $^{\mathrm{a}}$ & 843 & 100 & 843 & 100 & 843 & 100 \\
\hline
\end{tabular}

OPD, out-patient department; HM, hand movements.

Median visual acuity at first out-patient assessment $=6 / 24$.

Median visual acuity when listed for surgery $=6 / 36$.

Median visual acuity on admission for surgery $=6 / 60$.

${ }^{a}$ Complete records for visual acuity fields at all times. 
Table III. Distribution of best visual acuity in patient's better eye

\begin{tabular}{|c|c|c|c|c|c|c|}
\hline \multirow[b]{2}{*}{ Visual acuity } & \multicolumn{2}{|c|}{ At first OPD assessment } & \multicolumn{2}{|c|}{ At listing for surgery } & \multicolumn{2}{|c|}{ On admission for surgery } \\
\hline & $n$ & $\%$ & $n$ & $\%$ & $n$ & $\%$ \\
\hline $6 / 6$ to $6 / 12$ & 513 & 61 & 475 & 56 & 415 & 49 \\
\hline $6 / 18$ to $6 / 24$ & 206 & 24 & 214 & 25 & 244 & 29 \\
\hline $6 / 36$ to $6 / 60$ & 68 & 8 & 91 & 11 & 101 & 12 \\
\hline $3 / 60$ to $\mathrm{HM}$ & 56 & 7 & 63 & 8 & 83 & 10 \\
\hline Total $^{\mathrm{a}}$ & 843 & 100 & 843 & 100 & 843 & 100 \\
\hline
\end{tabular}

Median visual acuity at first out-patient assessment $=6 / 12$.

Median visual acuity when listed for surgery $=6 / 12$.

Median visual acuity on admission for surgery $=6 / 18$.

${ }^{a}$ Complete records for visual acuity fields at all times.

survey patients once referred to the hospital eye service is shown in Table I. The median wait for a first out-patient assessment was 2.64 months (first eye median wait $=2.64$ months, second eye median wait $=2.52$ months).

Overall $56 \%$ of patients were listed for surgery on presentation (median wait $=0$ months). Thirty-one per cent $(n=302)$ of patients had waited over a year to be listed. Sixty-seven per cent of first eyes (median wait $=0$ ) and $25 \%$ of second eyes (median wait 11.82 months) were listed on presentation.

After the decision for surgery had been made $59 \%$ of patients waited 6 months or less for admission for the procedure, the median wait being 4.8 months. The median waiting times for admission for first and second eyes were 4.56 and 5.34 months respectively.

Given these distributions, $70 \%$ of patients waiting more than 3 months for first out-patient assessment, $89 \%$ of patients who had waited more than 3 months to be listed for surgery and $92 \%$ of patients waiting more than 6 months for admission were visually impaired in the eye for surgery (visual acuity $6 / 18$ or less). About half of these patients were visually impaired in the better eye: $52 \%$ of patients waiting for more than 3 months for first assessment, $46 \%$ of patients waiting more than 3 months for listing and $49 \%(n=183)$ of patients who had been waiting for more than 6 months for admission.

\section{Visual Acuity}

Table II describes the distribution of best corrected visual

Table IV. Characteristics of post-operative management at 3 months

\begin{tabular}{lrr}
\hline 1. Visits to out-patient clinic $(n=918)$ & \\
No. of visits & $n$ & $\%$ \\
1 & 25 & 3 \\
2 & 326 & 36 \\
3 & 399 & 43 \\
4 & 105 & 11 \\
$>4$ & 63 & 7 \\
Mean number of visits $=2.87(\mathrm{SD}=1.00)$ & \\
\hline
\end{tabular}

2. Duration of post-operative medication $(n=873)$

$\begin{array}{cc}\text { No. of weeks } & n \\ \leqslant 6 & 265 \\ 7-8 & 239 \\ 9-10 & 124 \\ 11-12 & 77 \\ >12 & 168 \\ \text { Median duration }=7.43 \text { weeks } & \end{array}$

acuity in the eye having surgery. On presentation median acuity was $6 / 24$. At the time of listing for surgery median acuity was $6 / 36$ and on admission for surgery median acuity was $6 / 60$.

Median acuities for first eyes were $6 / 24,6 / 36$ and 6/60 and for second eyes $6 / 18,6 / 36$ and $6 / 60$, on presentation, at listing and on admission respectively.

Table III provides the distribution of acuity in the better eye at these times.

\section{Delivery of Surgery}

\section{Threshold for Surgery}

Table II also indicates that the threshold at which surgery is offered to patients is at a visual acuity of $6 / 18$ or less with median acuity of $6 / 36$. (This threshold was consistent when first and second eyes were considered separately.)

Only $11 \%(n=91)$ of patients were listed for surgery with a visual acuity of $6 / 12$ or better and all of them had a good acuity of $6 / 12$ or better in the fellow eye ( 28 were second eyes). Forty-nine per cent $(n=368)$ of the patients listed with a visual impairment (6/18 or less) in the eye for surgery $(n=752)$ were visually impaired in the fellow eye.

\section{Post-operative Management}

Table IV presents the features of post-operative management studied. The median length of stay for patients having in-patient surgery was 3 days. Twenty-two per cent
3. Visual rehabilitation

(a) Final refraction $(n=872)$

Performed

At hospital

By local optometrist

(b) Spectacles $(n=827)$

Dispensed

At hospital

By local optometrist

$\begin{array}{cc}n & \% \\ 657 & 75 \\ 447 & 68 \\ 210 & 32 \\ & \\ n & \% \\ 513 & 62 \\ 92 & 18 \\ 421 & 82\end{array}$

4. Status at 3 months $(n=909)$

Discharged

Follow-up $\stackrel{n}{305}$

604
$\%$

34 
Table V. Regional cataract operation rates

\begin{tabular}{|c|c|c|c|c|c|c|c|c|c|c|}
\hline \multirow[b]{2}{*}{ Region } & \multicolumn{4}{|c|}{ Crude weekly rate } & \multicolumn{2}{|c|}{ Crude annual rate } & \multirow[b]{2}{*}{ Rate ratio } & \multirow[b]{2}{*}{$p$} & \multicolumn{2}{|c|}{ Age-standardised rates } \\
\hline & $50-74$ yr & $\geqslant 75 \mathrm{yr}$ & All ages & $(95 \% \mathrm{CI})$ & All ages & $(95 \% \mathrm{CI})$ & & & Weekly rate & Annual rate \\
\hline Northern & 8.6 & 36.7 & 14.1 & (12.1 to 16.8$)$ & 693 & (580 to 806$)$ & 1.69 & $(<0.001)$ & 14.8 & 712 \\
\hline Yorkshire & 4.5 & 24.0 & 8.8 & (7.1 to 10.6$)$ & 425 & (341 to 509 ) & - & - & 8.8 & 424 \\
\hline Trent & 6.5 & 25.9 & 10.7 & (8.9 to 12.3$)$ & 512 & (431 to 590 ) & 1.23 & $(0.110)$ & 10.8 & 518 \\
\hline E. Anglia & 8.8 & 37.8 & 15.5 & (12.5 to 18.5$)$ & 743 & (600 to 888$)$ & 1.72 & $(<0.001)$ & 15.2 & 731 \\
\hline N. W. Thames & 6.2 & 31.8 & 11.9 & (9.8 to 14.0$)$ & 570 & (468 to 672 ) & 1.35 & $(0.026)$ & 11.9 & 571 \\
\hline N. E. Thames & 7.0 & 34.9 & 13.4 & (11.3 to 15.5$)$ & 642 & (542 to 744 ) & 1.49 & $(0.002)$ & 13.2 & 632 \\
\hline S. E. Thames & 6.5 & 32.9 & 13.0 & (10.9 to 15.0$)$ & 624 & (523 to 720 ) & 1.40 & $(0.008)$ & 12.4 & 595 \\
\hline S. W. Thames & 5.8 & 27.0 & 11.0 & (8.9 to 13.1$)$ & 528 & (428 to 629 ) & 1.19 & $(0.208)$ & 10.5 & 506 \\
\hline Wessex & 6.9 & 36.4 & 14.0 & (11.7 to 16.4 ) & 673 & (562 to 787 ) & 1.53 & $(0.001)$ & 13.5 & 647 \\
\hline Oxford & 6.4 & 32.1 & 11.7 & $(9.2$ to 14$)$ & 561 & (440 to 672 ) & 1.37 & $(0.034)$ & 12.1 & 580 \\
\hline S. Western & 4.6 & 32.8 & 11.6 & (9.6 to 13.6$)$ & 555 & (459 to 653 ) & 1.24 & $(0.105)$ & 10.9 & 521 \\
\hline W. Midlands & 6.8 & 34.2 & 12.4 & (10.7 to 14.1$)$ & 596 & (514 to 677 ) & 1.46 & $(0.002)$ & 12.9 & 618 \\
\hline Mersey & 6.3 & 32.5 & 11.7 & (9.3 to 14.2$)$ & 563 & (445 to 682 ) & 1.37 & $(0.031)$ & 12.1 & 580 \\
\hline N. Western & 5.6 & 36.4 & 12.5 & (10.5 to 14.4$)$ & 598 & (504 to 691 ) & 1.41 & $(0.007)$ & 12.4 & 597 \\
\hline Wales & 4.4 & 38.8 & 11.9 & $(9.7$ to 14.1$)$ & 572 & (466 to 677 ) & 1.36 & $(0.026)$ & 12.0 & 576 \\
\hline N. Ireland & 6.7 & 40.3 & 13.4 & (9.8 to 16.9$)$ & 643 & (473 to 811 ) & 1.60 & $(0.005)$ & 14.2 & 679 \\
\hline Scotland & 9.0 & 42.1 & 16.1 & (14.1 to 18.1$)$ & 773 & (677 to 869 ) & 1.85 & $(<0.001)$ & 16.3 & 783 \\
\hline
\end{tabular}

Crude operation rates presented per 100000 regional population (1990 estimates) of 50 years of age and greater.

Standardised operation rates presented per 100000 of UK population (1990 estimates) of 50 years of age and greater.

Rate ratios are presented with reference to the lowest observed weekly operation rate.

$(n=214)$ of patients had sutures removed by 3 months after surgery, with astigmatism being given as the indication for removal in $57 \%$ of cases (Fig. 1).

Sixty-six per cent $(n=604)$ of patients were still under follow-up 3 months after surgery. Reasons for continued follow-up were not identified in $30 \%(n=182)$ of patients as they had no surgically related complication, had been refracted and had achieved a good post-operative visual acuity of $6 / 12$ or better. Of these patients $26 \%(n=47)$ had undergone surgery to the second eye.

\section{Operation Rates}

Regional operation rates are presented in Table V. The variation observed in the crude weekly operation rates persists after standardisation. Rate ratios are presented with respect to the lowest observed weekly operation rate (Yorkshire), showing that except for three regions (Trent, South West Thames and South Western), the remainder have significantly higher operation rates.

When the regional operation rates are presented by age they are consistently about 5 times higher in the older age group ( 75 years and over) in all regions.

\section{DISCUSSION}

The survey week has been shown to be representative of clinical activity and no important differences were demonstrated between participants and non-participants in the survey. Consequently the cohort of patients in the survey period provided by the participating consultants

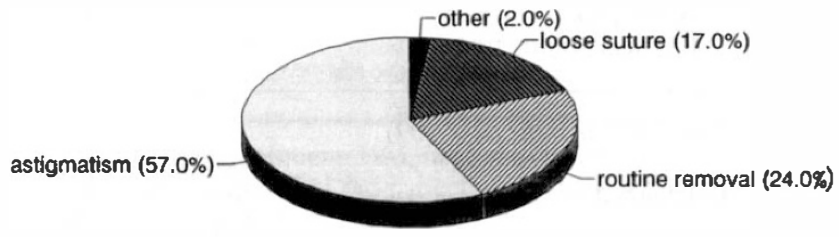

Fig. 1. Indications for suture removal $(\mathrm{n}=214)$. was considered to be a representative sample of all patients having cataract surgery in the UK in $1990 .{ }^{1}$

Cataract extraction is undoubtedly a high-volume surgical procedure, with over 105000 operations being performed annually within the NHS. ${ }^{1}$ These results indicate that cataract surgery is performed predominantly on patients of 75 years of age or more. The majority of patients have considerable levels of visual impairment by the time they present to the hospital eye service (median acuity of $6 / 24$ in the eye for surgery) and this is reflected in the finding that most are listed for surgery on presentation in the out-patient clinic. Although presentation in the second eye is earlier (median acuity 6/18) it appears to have a lower clinical priority for surgery as indicated by the longer median waiting time for listing of 11.82 months and by the fact that $32 \%$ of patients waiting for over 1 year were waiting for second eye surgery.

Thresholds for surgery have been observed to be decreasing since the introduction of microsurgical techniques and intraocular lenses.${ }^{6,7}$ Currently the threshold is at a visual acuity of $6 / 18$ or less for both first and second eyes. The median length of stay for in-patient cataract surgery has been falling steadily since $1975 .{ }^{8}$ With many initiatives for day case surgery taking place since the time of the survey, it is unlikely that lengths of stay will continue to fall as steeply in the future as in-patient cataract surgery will increasingly be reserved for special groups of patients.

Prior to the survey, consideration of general clinical consensus by the Audit Committee of the College of Ophthalmologists suggested that it would be reasonable to expect patients to be discharged 3 months after cataract surgery. Consequently, this time period was considered suitable for assessment of post-operative management and for short-term clinical outcomes.

The most striking feature of post-operative management was that only one third of patients were discharged 
by 3 months after surgery and in $30 \%$ of patients still under continued follow-up, no apparent reason was identified. Clearly this suggests that there are areas for improvement in post-operative management where unnecessary follow-up and hospital attendance may be avoided.

Regional operation rates have been presented only as an indicator of regional activity. The variation observed in regional operation rates persisting after age standardisation must be interpreted with caution. Although a difference of almost twofold has been observed between the lowest and highest regional operation rates an adequate explanation cannot be provided directly from the survey data.

The rates presented here have been determined from the numbers of operations performed in the survey week by participating consultants. Although the survey week was shown to be a representative period of clinical activity and no important differences were demonstrated between participants and non-participants in the survey ${ }^{1}$ it is not possible to quantify any random variation in activity that could have occurred as a consequence of sampling.

These rates refer only to cataract operations performed within the NHS and no allowance is made for those performed in the private sector. Patients having surgery for other types of cataract or having combined procedures were not included in the survey.

It is unlikely that there are major variations in the prevalence of cataract across regions. Since only 3.8\% of all operations were performed on Asian or African-Caribbean patients during the survey ${ }^{1}$ it is also unlikely that differences in the ethnic mix of regional populations would have contributed to the variation observed.

An obvious consideration would be the availability of surgeons. At the time of the survey, only Scotland fulfilled

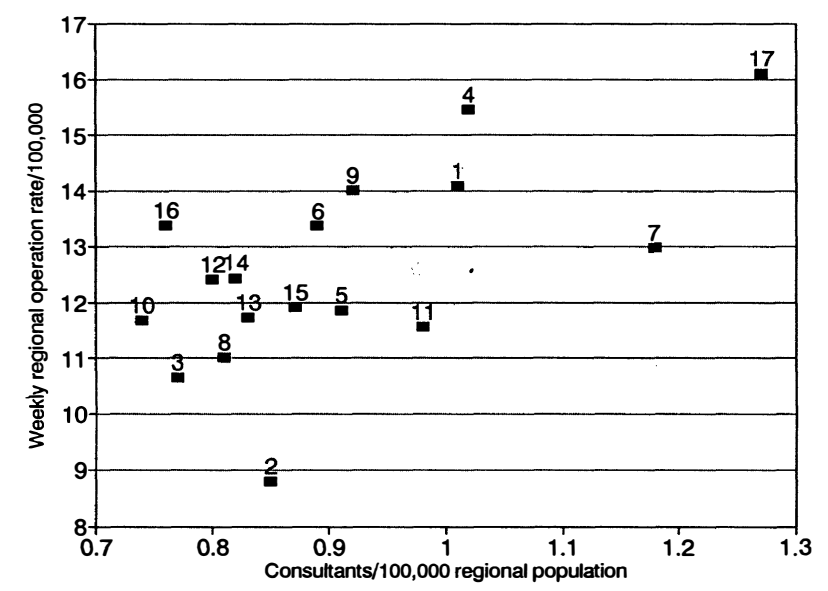

Fig. 2. Regional operation rates by availability of consultants. Regions: 1, Northern; 2, Yorkshire; 3, Trent; 4, E. Anglia; 5, N.W. Thames; 6, N.E. Thames; 7, S. E. Thames; 8, S.W. Thames; 9, Wessex; 10, Oxford; 11, S. Western; 12, W. Midlands; 13, Mersey; 14, N. Western; 15, Wales; 16, N. Ireland; 17, Scotland. the recommendations of the College of Ophthalmologists for a ratio of 1 consultant per 80000 of the regional population. ${ }^{9}$ Fig. 2 shows the association between crude regional operation rate and number of consultant ophthalmologists per 100000 of the regional population who regularly performed cataract surgery. When all regions are included in the analysis, an association between operation rates and the number of consultants is observed (correlation coefficient $r=0.62, p=0.007$ ). When Scotland is treated as an outlier and excluded from the analysis no correlation between operation rates and number of consultants is observed (correlation coefficient $r=0.45$, $p=0.078$ ). (A similar observation emerged when the total number of consultants in each region was considered separately.)

The National Cataract Surgery Survey was designed to describe current surgical activity for age-related cataract in the UK. It has achieved its objectives and related process (provision of medical/surgical care) to the short-term clinical outcomes of cataract surgery, providing an overview of the national experience. By collecting prospective clinical data the survey database represents the actual experience of a sample of all patients undergoing surgery for age-related cataract in the UK in 1990. These data may be used for local and regional audit, and contribute to the development of guidelines for the management of agerelated cataract. Repeating the survey at regular intervals would provide a practical method of evaluating and auditing surgical practice for national trends in the management of age-related cataract.

I am grateful to all the ophthalmologists who participated in the survey and without whose support it would not have been possible; the Audit Committee; Miss N. Mahmood and the staff of the College of Ophthalmologists. The Department of Health provided core funding for the conduct of this project.

Key words: Cataract surgery, Process.

\section{REFERENCES}

1. Courtney P. The national cataract surgery survey. I. Method and descriptive features. Eye 1991;6:487-92.

2. Desai P. The national cataract surgery survey. II. Clinical outcomes. Eye 1993;7:489-94.

3. Moorfields Eye Hospital Business Plan 1992/93.

4. Central Statistics Office. Annual Abstract of Statistics 1992.

5. Gardner SB, Winter PD, Gardner MJ. Confidence interval analysis. London: BMJ, 1989.

6. Batterbury M, Khaw PT, Hands R, Elkington AR. The cataract explosion: the changing pattern of diagnoses of patients attending an out-patient department. Eye 1991;5:369-72.

7. Jay JL, Devlin ML. The increasing frequency of surgery for cataract. Eye 1990;4:127-31.

8. Williams M, Frankel S, Coast J, Nanchahal K, Donovan J. DHA Project: research programme epidemiologically based needs assessment. Cataract Surgery. Health care evaluation unit. University of Bristol, 1992.

9. College of Ophthalmologists. Hospital Eye Services, 1991. 